\title{
Study of antioxidant, antibacterial and anti-inflammatory activity of cinnamon (Cinamomum tamala), ginger (Zingiber officinale) and turmeric (Curcuma longa)
}

\author{
Ranjit Thakur $^{1,2}$, Kamlesh Yadav ${ }^{3}$, Khim Bahadur Khadka ${ }^{3}$ \\ ${ }^{1}$ Department of Biochemistry, Universal Science College, Kathmandu, Nepal \\ ${ }^{2}$ Department of Biochemistry, People's Dental College and Hospital Nayabazar, Kathmandu, Nepal \\ ${ }^{3}$ Biochemistry, Pokhara University, Kathmandu, Nepal
}

Email address:

ranjitthakur008@gmail.com (R. Thakur)

\section{To cite this article:}

Ranjit Thakur, Kamlesh Yadav, Khim Bahadur Khadka. Study of Antioxidant, Antibacterial and Anti-Inflammatory Activity of Cinnamon (Cinamomum Tamala), Ginger (Zingiber Officinale) and Turmeric (Curcuma Longa). American Journal of Life Sciences.

Vol. 1, No. 6, 2013, pp. 273-277. doi: 10.11648/j.ajls.20130106.16

\begin{abstract}
Ethanol extract of ginger, turmeric and cinnamon was assessed for its antioxidant, antimicrobial and antiinflammatory activity. The antioxidant activity was determined by measuring FRAP (ferric reducing-antioxidant power) assay. The antibacterial efficacy was determined using paper disc method against different gram negative bacterial and sensitivity in terms of zones of inhibition of all extract were also determined. In vitro anti-inflammatory activity was evaluated using Proteinase inhibitory assay. Aspirin was used as a standard drug for the study of anti-inflammatory activity. The result shows that the ethanolic extract of the ginger and turmeric were effective against all the bacteria tested, where as the ethanolic extract of cinnamon was failure in inhibiting the growth of all bacteria tested. The ethanolic extract of ginger possessed strong antioxidant activity in FRAP method. The ethanolic extracts of ginger shows the largest antioxidant FRAP value where as the turmeric ethanolic extract showed the minimum antioxidant FRAP value which were given as 3.86 $\mathrm{mM} / 100 \mathrm{gm}$ and $0.38 \mathrm{mM} / 100 \mathrm{gm}$ respectively. The FRAP value for the ethanolic cinnamon extract was found to be 0.40 $\mathrm{mM} / 100 \mathrm{gm}$. The ethanolic extract of ginger and turmeric also showed in vitro anti-inflammatory activity by inhibiting the proteinase activity. Proteinase activity was significantly inhibited by ginger $(78.49 \%)$, turmeric $(66.48 \%)$ and cinnamon $(58.72 \%)$ at $800 \mathrm{ug} / \mathrm{ml}$ concentration. From the result it is concluded that the ginger, turmeric and cinnamon ethanol extract showed the antioxidant and anti-inflammatory activity where as the ginger and turmeric ethanol extract exhibited the antibacterial activity.
\end{abstract}

Keywords: Cinamomum Tamala, Zingiber Officinale, Curcuma Longa, Antioxidant, Antimicrobial, Anti-Inflammatory

\section{Introduction}

The increase in prevalence of multiple drug resistance has shown the development of new synthetic antibacterial, antioxidative and anti-inflammatory drugs; moreover, the new drug is necessary to search for new antimicrobial, antioxidant and anti-inflammatory sources from alternative sources. Phytochemicals from medicinal plants showing antimicrobial, antioxidant and anti-inflammatory activities have a potential of filling this need because their structures are different from those of the more studied plants ${ }^{[1]}$ In this growing interest, many of the phytochemical bioactive compounds from a medicinal plants have shown many pharmacological activities. ${ }^{[2]}$ The rapid emergence of multiple drug resistance strains of pathogens to current antimicrobial agents has generated an urgent intensive for new antibiotics for medicinal plants. Free radicals which have one or more unpaired electrons (superoxide, hydroxyl, peroxyl) are produced in normal or pathological cell metabolism and the compounds that can scavenge free radicals have great potential in ameliorating the diseases and pathological cells. ${ }^{[3]}$ Antioxidants thus play an important role to protect the human body against damage by reactive oxygen species. These free radicals are the main culprits in lipid peroxidation. Plants containing bioactive compounds have been reported to possess strong antioxidant properties. In many inflammatory disorders there is excessive activation of phagocytes, production of $\mathrm{O} 2, \mathrm{OH}$ radicals as well as non free radicals species $\left(\mathrm{H}_{2} \mathrm{O}_{2}\right)$, 
which can harm severely tissues either by powerful direct oxidizing action or indirect with hydrogen peroxide and $\mathrm{OH}$ radical formed from $\mathrm{O} 2$ which initiates lipid peroxidation resulting in membrane destruction. Tissue damage then provokes inflammatory response by production of mediators and chemotatic factors. [4]

Study of antioxidant, antibacterial and anti-inflammatory activity was done using Cinnamon (Cinamomum tamala), Ginger (Zingiber officinali) and Turmeric (Curcuma longa). All of these three samples were used in most of the diseases in the 19th century and were a strong part of the traditional medicine.

The literatire survey indicates that no reports are available from Nepal regarding antimicrobial, antioxidant and antiinflammatory activity of ginger, turmeric and cinnamon. In present study was aimed to examine the ethanolic extract of ginger, turmeric and cinnamon for antimicrobial, antioxidant and anti-inflammatory properties using standard methods. The findings from this work may add to the overall value of the medicinal potential of the plants.

\section{Materials and Methods}

The samples was collected in July 2012 for the local market of Kathmandu ,Nepal. The samples were selected based on the daily consumption by the Nepalese people.

\subsection{Extract Preparation}

All the three samples (ginger, turmeric, and cinnamon) were air dried at room temperature for 4 weeks to get consistent weight. The dried parts were later grinded to power. The dried parts were used for extract using ethanol. The extracts were filtered using Buckner funnel and Whatmann's No. 1 filter paper. Each filtrate was concentrated to dryness under reduced pressure at $40{ }^{0} \mathrm{C}$ using a rotatory evaporator. Each extract was resuspended in the solvent ethanol to yield a $50 \mathrm{mg} / \mathrm{ml}$ stock solution. [5] [6]

\subsection{Determination of Antimicrobial Activity}

Strains of Klebsiella pneumonia, Escherichia coli and Pseudomonas aeruginosa bacteria were obtained from stock cultures preserved at $-4{ }^{\circ} \mathrm{C}$ at research laboratory of Universal science college lalitpur, Nepal. All the bacteria tested were Gram negative. All bacteria were grown on nutrient agar media.

\subsection{Paper Disc Method}

Diameter of zone of inhibition was determined using the paper disc diffusion method as described by Lai et al. (2009) and Adedapo et al. (2008). ${ }^{[7]}{ }^{6]}$ A swab of the bacteria suspension containing $1 \times 10^{8} \mathrm{cfu} / \mathrm{ml}$ was spread on to Petri plates containing nutrient agar media. Each extracts were dissolved in ethanol to final concentration of $10 \mathrm{mg} / \mathrm{ml}$. sterile filter paper discs $(6 \mathrm{~mm}$ in diameter) impregnated with $1 \mathrm{mg}$ of plant extracts were placed on culture plates. The plates were incubated at $37^{\circ} \mathrm{C}$ for $24 \mathrm{~h}$. The ethanol served as negative control while the standard Ampicillin $(10 \mu \mathrm{g})$ discs were used as positive controls. Antimicrobial activity was indicated by the presence of clear inhibition zone around the discs. The assay was repeated thrice and mean of three experiments was recorded.

\subsection{Determination of Antioxidant Activity}

In order to investigate the antioxidant properties of the examined extracts ferric ion reducing antioxidant power (FRAP) assay was used. The method for determining the ferric reducing ability has been taken in modified form from the method used by Benzie and Strain.

\subsection{FRAP Assay}

FRAP reagents was freshly prepared by mixing acetate buffer (300 mM, pH 3.6), TPTZ solution (10 mM) and $\mathrm{FeCl}_{3}(20 \mathrm{mM})$ in the ratio of $10: 1: 1$. Each sample $(10 \mu \mathrm{l})$ of $50 \mathrm{mg} / \mathrm{ml}$ was added to $3 \mathrm{ml}$ of freshly prepared FRAP reagent and stirred and after 5 minute absorbance was measured at $593 \mathrm{~nm}$, using FRAP working solution as blank. Thereafter, samples were allowed to stand for 4 minutes and absorbance is again taken at $593 \mathrm{~nm}$. The results were expressed in $\mathrm{mM} / 100 \mathrm{gm}$.

\subsection{In Vitro Anti-Inflammatory Activity}

\subsubsection{Protein Inhibitory Action}

The test was performed according to the modified method of Oyedepo et al. The reaction mixture $(2 \mathrm{ml})$ was containing $0.06 \mathrm{mg}$ trypsin, $1 \mathrm{ml} 20 \mathrm{mM}$ Tris $\mathrm{HCl}$ buffer (pH 7.4) and $1 \mathrm{ml}$ test sample of different concentrations. The mixture was incubated at $37 \mathrm{oC}$ for $5 \mathrm{~min}$ and then $1 \mathrm{ml}$ of $0.8 \%(\mathrm{w} / \mathrm{v})$ casein was added. The mixture was incubated for an additional $20 \mathrm{~min} .2 \mathrm{ml}$ of $70 \%$ Perchloric acid was added to terminate the reaction. Cloudy suspension was centrifuged and the absorbance of the supernatant was read at $210 \mathrm{~nm}$ against buffer as blank. The experiment was performed in triplicate. The percentage inhibition of Proteinase inhibitory activity was calculated.

Percentage inhibition $=($ Abs control - Abs sample $) \mathrm{X}$ 100/ Abs control

\subsection{Statistical Analysis}

The results are expressed as the mean \pm SD for three replicates. The correlation coefficient value(r) was calculated between Proteinase inhibitory activity and the concentration of test sample.

\section{Results}

\subsection{Antioxidant Activity}

The FRAP value of our sample was expressed in micro molar per $100 \mathrm{gm}(\mathrm{mM} / 100 \mathrm{gm})$. The reducing ability of our sample extract Cinnamon (Cinamomum tamala), ginger (Zingiber officinale) and turmeric (Curcuma longa) was in the range of 0.38 to $3.86 \mathrm{mM} / 100 \mathrm{gm}$ (Table1). The 
antioxidant potential of the ethanol extract of Cinnamon (Cinamomum tamala), ginger (Zingiber officinale) and turmeric (Curcuma longa) were estimated from their ability to reduce TPTZ-Fe (III) complex to TPTZ-Fe (II). The FRAP values for the ethanol extract of zinger was found to be maximum where as the FRAP values for the ethanol exact of turmeric was found to be minimum (Figure 1), which was $3.86 \mathrm{mM} / 100 \mathrm{gm}$ and $0.38 \mathrm{mM} / 100 \mathrm{gm}$ respectively. Like this the FRAP value of ethanol extract of Cinnamon (Cinamomum tamala) was found to be $0.40 \mathrm{mM} / 100 \mathrm{gm}$.

\subsection{Antimicrobial Assay}

The antimicrobial activities of ethanolic extract of cinnamon (Cinamomum tamala), ginger (Zingiber officinale) and turmeric (Curcuma longa) gave different zones of inhibition on the organisms tested (Table 2). The ethanolic turmeric extract inhibited the growth of all the bacteria isolates, but the ethanolic extract of cinnamon did not showed any significant effect on the bacterial isolates that we have tested. The ethanolic ginger extract showed more potent against E.coli. and moderately inhibited the P. aeruginosa, K. pneumonia. The E.coli species was more affected by ginger in ethanolic extract.All the bacterial isolates that we have tested were showed no response against ethanolic extract of cinnamon.

\subsection{Anti-Inflammatory Properties}

The ethanolic extract of cinnamon, ginger, and turmeric exhibited significant Antiproteinase activity at different concentration (Table 3).The ethanolic extract of ginger showed the maximum inhibition $78.49 \pm 0.40 \%$ at 800 $\mu \mathrm{g} / \mathrm{ml}$ and showed the minimum inhibition $20.29 \pm 1.33 \%$ at $50 \mu \mathrm{g} / \mathrm{ml}$ (Figure 2).Like this the ethanolic extract of turmeric showed the maximum inhibition $66.48 \pm 0.60 \%$ at $800 \mu \mathrm{g} / \mathrm{ml}$ and showed the minimum inhibition $16.12 \pm 0.36 \%$ at $50 \mu \mathrm{g} / \mathrm{ml}$ (Figure 3).The ethanolic extract of cinnamon showed the maximum inhibition $58.72 \pm 0.50 \%$ at $800 \mu \mathrm{g} / \mathrm{ml}$ and showed the minimum inhibition $10.12 \pm 1.24 \%$ at 50 $\mu \mathrm{g} / \mathrm{ml}$ (Figure 4).It is found that the maximum inhibition was observed from ethanolic ginger extract $(78.49 \pm 0.40 \%)$ in decreasing order was turmeric $(66.48 \pm 0.60 \%)$ and cinnamon ethanolic extract $(58.72 \pm 0.50 \%)$ at $800 \mu \mathrm{g} / \mathrm{ml}$. The correlation coefficient value (r) between concentration and protease inhibition was calculated 0.98 for ginger, 0.98 for turmeric and 0.99 for cinnamon. The standard Aspirin $(92.87 \pm 0.76 \%)$ drug showed the maximum Proteinase inhibitory action. (Table 3)

Table 1. Total antioxidant (FRAP) activities of ethanol extract of Cinnamon (Cinamomum tamala), ginger (Zingiber officinali) and turmeric (Curcuma longa)

\begin{tabular}{ll}
\hline Extract & FRAP \\
Ethanol extract & mM/100gm \\
\hline Ginger & $3.86 \pm 0.06$ \\
Turmeric & $0.38 \pm 0.06$ \\
Cinnamon & $0.40 \pm 0.05$ \\
\hline
\end{tabular}

Repeated the experiments three times for each replicates
Table 2. In vitro inhibition assay from ethanolic extract of Cinnamon (Cinamomum tamala), ginger (Zingiber officinali) and turmeric (Curcuma longa)

\begin{tabular}{llll}
\hline Bacterial Pathogens & Cinnamon & Ginger & turmeric \\
\hline E. coli & - & ++ & + \\
P. aeruginosa & - & + & + \\
K. pneumonia & - & + & + \\
\hline
\end{tabular}

Repeated the experiments three times for each replicates

Table 3. Effect of ethanol extract of Cinnamon (Cinamomum tamala), ginger (Zingiber officinale) and turmeric (Curcuma longa) on Proteinase inhibitory activity percentage inhibition

\begin{tabular}{lll}
\hline Test Sample & $\begin{array}{l}\text { Concentration } \\
(\mathbf{u ~ g / m l )}\end{array}$ & $\begin{array}{l}\text { \% Inhibition } \\
\text { Proteinase Inhibition }\end{array}$ \\
\hline \multirow{3}{*}{ Ginger } & 50 & $20.29 \pm 1.33$ \\
& 100 & $22.13 \pm 0.67$ \\
& 200 & $26.31 \pm 1.63$ \\
& 400 & $38.36 \pm 0.82$ \\
& 600 & $62.72 \pm 1.35$ \\
Turmeric & 800 & $78.49 \pm 0.40$ \\
& 50 & $16.12 \pm 0.36$ \\
& 100 & $20.42 \pm 1.56$ \\
& 200 & $23.82 \pm 0.52$ \\
& 400 & $30.26 \pm 0.62$ \\
& 600 & $56.34 \pm 1.38$ \\
& 800 & $66.48 \pm 0.60$ \\
& 50 & $10.12 \pm 1.24$ \\
& 100 & $13.16 \pm 0.62$ \\
& 200 & $17.32 \pm 1.34$ \\
& 400 & $28.42 \pm 0.42$ \\
& 600 & $52.32 \pm 1.38$ \\
& 800 & $58.72 \pm 0.50$ \\
& 100 & $56.45 \pm 0.45$ \\
& 200 & $92.87 \pm 0.76$ \\
\hline
\end{tabular}

Repeated the experiments three times for each replicates

\section{Discussion}

In recent years, the search for possessing antioxidant, antimicrobial and anti inflammatory properties have been on the rise due to their potential use in the therapy of various chronic and infectious diseases. Epidemiology and experimental studies have implicated oxidative cellular damage arising from an imbalance between free radical generating and scavenging systems as the primary cause of cardio-vascular diseases, cancer, aging etc. ${ }^{[8]}$ Due to risk of adverse effects encountered with the use of synthetic antibiotics, medicinal plants may offer an alternative source for antimicrobial agent with significant activity against pathogenic and infective microorganisms. In addition, a number of antibiotics have lost their effectiveness due to the development of resistant strains, mostly through the expression of resistance genes ${ }^{[9]}$

Results of our findings confirmed the use of our sample, ginger and turmeric as traditional medicine. Whereas the cinnamon is also used as a traditional medicine except for 
bacterial pathogens because it gives negative results against bacterial pathogens that means it does not inhibit the growth of bacterial strains. We found strong antioxidants, anti bacterial and anti inflammatory activities specifically in the ethanolic ginger and turmeric extracts. Ethanolic cinnamon extracts is failure to shows potent anti bacterial activities but it is also effectiveness against antioxidant and inhibit the inflammation. It is also shown that plants phenolic compounds have been found to possess potent antioxidants, [10] [11] [12] antimicrobial, [13] and anti inflammatory activity. ${ }^{[14]}{ }^{[15]}$

The flavonoids from plant extracts have been found to possess antioxidants, antimicrobial and anti inflammatory properties in various studies. ${ }^{[16][17][18]}$ The presence of terpenoids have shown as antimicrobial, ${ }^{[19]}$ antioxidant ${ }^{[20]}$ and anti-inflammatory properties. ${ }^{[21]}$ Strong presence of tannins in all extracts may explain its potent bioactivities as tannins are known to possess potent antimicrobial activities, antioxidants, ${ }^{[22]}$ and anti-inflammatory properties. ${ }^{[23]}$ The Saponins have already shown as antimicrobial activity, ${ }^{\text {24] }}$ antioxidant activity, ${ }^{[25]}$ and anti-inflammatory activity. ${ }^{[26]}$ Though we have not performed the phytochemical test the above discussion support that there may be the presence of different polyphenolic compounds such as flavonoids, tannins, terpenoids, phenols, Saponins.

Proteinase has been implicated in arthritic reactions. Neutrophils are known to be a source of Proteinase which carries in their lysosomal granules many serine Proteinase. It was previously reported that leukocytes Proteinase play important role in the development of tissue damage during in inflammatory reactions and significant level of protection was provided by Proteinase inhibitors. ${ }^{[27]}$ Recent studies have shown that many flavonoids and related polyphenols contributed significantly to the antioxidant and anti inflammatory activities of many plants. Hence, the presence of bioactive compounds in the ethanolic extract of Ginger and Turmeric may contribute to its, antimicrobial, antioxidant and anti-inflammatory activity where as Cinnamon is failure to give antimicrobial properties, but possess the potent antioxidant and anti inflammatory properties.

\section{Acknowledgements}

We thank to Biochemistry Department of Universal Science College, Mr. Kamlesh yadav and Mr. Khim bahadur khadka, my student in B.SC Biochemistry program for technical support.

\section{References}

[1] Fabricant DS, Fansworth NR (2001). The value of plants used in traditional medicine for drug discovery. Environ. Health Persp, 109: 69-75.

[2] Prachayasittikul S, Buraparuangsang P, Worachartcheewan A, Isarankura-Na-Ayudhya C, Ruchirawat S,
Prachayasittikul V (2008). Antimicrobial and antioxidant activity of bioreactive constituents from Hydnophytum formicarum Jack. Molecular, 13: 904-921.

[3] Halliwell B (1995). How to characterize antioxidant: an update. Biochem. Socie. Symp, 61:85-91.

[4] Lewis DA (1989). In: anti-inflammatory drugs from plants and marine sources. Basel: Bikhauser Verlag. Pp.135.

[5] Taylor RSL, Edel F, Manandhar NP, Towers GHN (1996). Antimicrobial activity of Southern Nepalese medicinal plants. J. Ethnopharmacol., 45: 67-70.

[6] Adedapo AA, Jimoh FO, Koduru S, Afolayan AJ, Masika PJ (2008). Antibacterial and Antioxidant properties of the methanol extracts of the leaves and stems of Calpurnia aurea. BMC Compl. Altern Med., 8: 53.

[7] Lai HY, Lim YY, Tan SP (2009). Antioxidative, tyrosinase inhibiting and antibacterial activities of leaf extracts from medicinal ferns. Biosci. Biotech. Biochem, 73: 1362-1366.

[8] Halliwell B (1996). Antioxidants in human health and disease. Annu. Rev. Nutr., 6: 33-50.

[9] Berahou AA, Auhmani A, Fdil N, Benharref A, Jana M, Gadhi CA (2007). Antibacterial activity of Quercus ilex bark's extracts. J. Ethnopharm., 112: 426-429.

[10] Adedapo AA, Jimoh FO, Koduru S, Masika PJ, Afolayan AJ (2009). Assessment of the Medicinal potentials of the methanol extracts of the leaves and stems of Buddleja saligna. BMC Compl. Altern Med., 9:21.

[11] Adesegun SA, Fajana A, Orabueze CI, Coker HAB (2009). Evaluation of antioxidant properties Of Phaulopsis fascisepala C.B.Cl. (Acanthaceae). Evid. Based Compl. Altern. Med., 6: 227- 231.

[12] Lai HY, Yau YY, Kim KH (2010). Blechnum orientale Linn - a fern with potential as antioxidant, anticancer and antibacterial agent. BMC Complem. Altern. Med., 10: 15

[13] Alcaraz LE, Blanco SE, Puig ON, Tomas F, Ferretti FH (2000). Antibacterial activity of flavonoids against methicillin-resistant Staphylococcus aureus strains. J. Theor. Biol., 205: 231-240.

[14] Sakat S, Juvekar AR, Gambhire MN (2010). In vitro antioxidant and anti-inflammatory activity of methanol extract of Oxalis corniculata Linn. I. J. Pharm. Pharm. Sci., 2: $146-155$.

[15] Garg VKR, Jain M, Sharma PKR, Garg G (2010). Anti inflammatory activity of Spinacia oleracea. Intern. J. Pharma Prof. Res., 1: 4.

[16] Lin Y, Shi R, Wang X, Shen HM (2008). Luteolin, a flavonoid with potential for cancer prevention and therapy. Curr. Can. Drug Targ. 8: 634- 46.

[17] Lopez-Lazaro M (2009). Distribution and biological activities of the flavonoid luteolin. Mini Rev. Med. Chem., 9: 31-59.

[18] Amaral S, Mira L, Nogueira JM, da Silva AP, Florencio MH (2009). Plant extracts with anti-inflammatory properties--a new approach for characterization of their bioactive compounds and establishment of structure-antioxidant activity relationships. Bioorg. Med. Chem., 17: 1876-1883. 
[19] Singh B, Singh S (2003). Antimicrobial activity of terpenoids from Trichodesma amplexicaule Roth. Phyto. Res., 17: 814-816.

[20] Grassman J (2005). Terpenoids as plant antioxidants. Vitam. Horm, 72: 505-535.

[21] Neukirch H, D'Ambrosio M, Sosa S, Altinier G, Loggia RD, Guerriero A (2005). Improved anti- inflammatory activity of three new terpenoids derived, by systematic chemical modifications, from the abundant triterpenes of the flowery plant Calendula officinalis. Chem. Biodiv., 2: 657-671.

[22] Zhang LL, Lin YM (2008). Tannins from Canarium album with potent antioxidant activity. J. Zhejiang Univ. Sci. B., 9: 407-415.

[23] Fawole OA, Amoo SO, Ndhlala AR, Light ME, Finnie JF, Van Staden J (2010). Anti-inflammatory, ant cholinesterase, antioxidant and phytochemical properties of medicinal plants used for pain-related ailments in South Africa. J. Ethnopharmacol., 127: 235-241.
[24] Mandal P, Babu SSP, Mandal NC (2005). Antimicrobial activity of saponins from Acacia auriculiformis. Fitoterapia, 76: 462-465.

[25] Gulcin L, Oktay M, Kufrevioglu IO, Aslan A (2004). Determination of antioxidant activity of Lichen Cetraria islandica (L.) Ach. J. Ethnopharm., 79: 325-329.

[26] Gepdireman A, Mshvildadze V, Suleyman H, Elias R (2005). Acute anti-inflammatory activity of four saponins isolated from ivy: alphahederin, hederasaponin- $\mathrm{C}$, hederacolchiside$\mathrm{E}$ and hederacolchiside- $\mathrm{F}$ in carrageenan-induced rat paws edema. Phytomedicine, 12: 440-444.

[27] Das SN, Chatterjee S (1995). Long term toxicity study of ART-400. Indian Indigenous Med., 16: 117-123. 